\title{
XPC Lys939Gln polymorphism contributes to colorectal cancer susceptibility: evidence from a meta-analysis
}

Qiliu Peng ${ }^{1}$, Xianjun Lao ${ }^{1}$, Weizhong Tang ${ }^{2}$, Zhiping Chen ${ }^{3}$, Ruolin $\mathrm{Li}^{4}$, Xue Qin ${ }^{{ }^{*}}$ and Shan $\mathrm{Li}^{1}$

\begin{abstract}
Background: Published studies investigating the association between XPC Lys939Gln polymorphism and colorectal cancer (CRC) risk reported inconclusive results. We performed a meta-analysis to derive a precise estimation of the relationship.
\end{abstract}

Methods: A comprehensive literature search was done in databases PubMed, EMBASE, and Cochrane library up to December 2013. The association between XPC Lys939GIn polymorphism and CRC risk was assessed by odds ratios (ORs) together with their 95\% confidence intervals (Cls).

Results: Eight studies with 3,301 cases and 4,177 controls were included in the meta-analysis. We observed that the XPC Lys939GIn polymorphism was correlated with an increased CRC risk when all studies were pooled into the meta-analysis (GIn/lys vs. Lys/Lys: OR =1.293, 95\% Cl 1.169-1.430, $P=0.000 ; \mathrm{Gln} / \mathrm{G} \ln +\mathrm{Gln} / \mathrm{lys}$ vs. Lys/Lys: OR $=1.260$, 95\% Cl 1.145-1.388, $P=0.000$ ). In stratified analyses by ethnicity, smoking, and study quality, significant increased CRC risk was found in Asians (Gln/lys vs. Lys/Lys: $O R=1.345,95 \%$ Cl 1.187-1.523, P=0.000; Gln/Gln + Gln/lys vs. Lys/Lys: $\mathrm{OR}=1.317,95 \% \mathrm{Cl} 1.170-1.484, P=0.000)$, nonsmokers (Gln/Gln + Gln/lys vs. Lys/Lys: OR $=1.286,95 \% \mathrm{Cl}$ 1.020-1.622, $P=0.033$ ), and high quality studies. In subgroup analysis by source of control, significant increased CRC risk was found in both hospital-based studies and population-based studies. However, in subgroup analysis according to cancer location, no any significant association was detected.

Conclusions: This meta-analysis suggests that the XPC is a candidate gene for CRC susceptibility. The XPC Lys939GIn polymorphism may play an important role in CRC development among Asians and nonsmokers. Further large and well-designed studies are needed to confirm this association.

Virtual Slides: The virtual slide(s) for this article can be found here: http://www.diagnosticpathology.diagnomx.eu/ vs/1665902729125948

Keywords: Colorectal cancer, XPC, Polymorphism, Meta-analysis

\section{Background}

Colorectal cancer (CRC) is one of the most common cancers and is the third leading cause of cancer-related death worldwide [1,2]. In Europe and the USA, CRC represents one of the main causes of cancer deaths $[1,3]$. In Asia, CRC is the fourth leading cause of mortality by cancer, and its incidence is increasing [4,5]. In recent years, the incidence of CRC is increasing in China,

\footnotetext{
* Correspondence: qinxue919@126.com

'Department of Clinical Laboratory, First Affiliated Hospital of Guangxi Medical University, Nanning 530021, Guangxi, China

Full list of author information is available at the end of the article
}

which accounts for about $6.5 \%$ of total cancers in urban areas and $4.6 \%$ in rural areas [6]. Previous epidemiological studies have identified dietary factors, such as consumption of meat, especially red meat, alcohol consumption, and cigarette smoking as possible risk factors for the development of CRC $[7,8]$. However, most individuals exposed to these known dietary risk factors never develop CRC while many CRC cases develop among individuals without those known risk factors, suggesting that other factors such as genetic factors also play important roles in colorectal carcinogenesis.

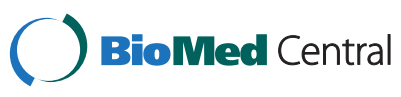

(c) 2014 Peng et al.; licensee BioMed Central Ltd. This is an Open Access article distributed under the terms of the Creative Commons Attribution License (http://creativecommons.org/licenses/by/4.0), which permits unrestricted use, distribution, and reproduction in any medium, provided the original work is properly credited. The Creative Commons Public Domain Dedication waiver (http://creativecommons.org/publicdomain/zero/1.0/) applies to the data made available in this article, unless otherwise stated. 
The xeroderma pigmentosum complementation group $\mathrm{C}$ (XPC) is one of the key members in the nucleotide excision repair (NER) pathway [9]. The NER pathway is the primary mechanism for removal of adducts from DNA, and thus is an important part of the cellular defense against a large variety of structurally unrelated DNA lesions. The XPC binds to HR23B and forms the XPC-HR23B complex, which is involved in the DNA damage recognition and DNA repair initiation in the NER pathway and the binding of XPC to damaged DNA is the rate-limiting step for NER [10-12]. The XPC gene is located at chromosome 3p25 and contains 16 exons and 15 introns. There are at least 687 reported single nucleotide polymorphisms (SNPs) in the XPC gene region (http://www.ncbi.nlm.nih.gov/snp/). Among all the identified SNPs, Lys939Gln polymorphism has received much attention in recent years. It is a substitution of lysine for glutamine in exon 15 of the XPC gene [13], and the variant 939Gln allele have been reported to correlated with reduced DNA repair activity and increased cancer risk [14-16].

Over the last two decades, several molecular epidemiological studies have evaluated the association between XPC Lys939Gln polymorphism and CRC risk, but the results remain controversial and inconclusive. For genetic association studies that check candidate polymorphisms, sample size is an important influencing factor for study accuracy. Small sample size might have insufficient power to explore a true association of modest effect [17], especially for complex multifactorial disease such as CRC [18]. Combining data from all eligible studies by meta-analysis has the advantage of increasing statistical power and reducing random error and obtaining precise estimates for some potential genetic associations. Therefore, in this study, we conducted a quantitative meta-analysis including all eligible studies.

\section{Methods}

\section{Search strategy}

We searched Pubmed, Embase and Cochrane library databases for all articles on the association between XPC Lys939Gln polymorphism and CRC risk using the following combined keywords: 'xeroderma pigmentosum group C', 'XPC', 'colon cancer', 'rectal cancer' and 'colorectal cancer'. The latest search was done in December 2013, without any language restriction. Additional articles were identified through the references cited in the first series of articles selected. Articles included in the meta-analysis were in any language, with human subjects, published in the primary literature and had no obvious overlap of subjects with other studies. Among overlapping reports, only the studies with more information on origin of cases/controls were retained. The study was performed according to the proposal of Meta-analysis of Observational Studies in Epidemiology group (MOOSE) [19].

\section{Selection criteria}

The following inclusion criteria were used for literature selection: (i) Case-control or cohort studies which evaluated the association between XPC Lys939Gln polymorphism and CRC risk; (ii) sufficient genotype data were presented to calculate the odds ratios (ORs) and 95\% confidence intervals (95\% CIs); (iii) control population did not contain malignant tumor patients. Major reasons for exclusion of studies were (i) review, or metaanalysis, or letter, or comment; (ii) duplicated studies, or studies without raw data we need; and (iii) studies that focused on HNPCC or FAP. Family-based studies of pedigrees with several affected cases per family were also excluded, because their analysis is based on linkage considerations.

\section{Data extraction}

Two authors (Qiliu Peng and Xianjun Lao) independently reviewed and extracted data from all eligible studies. Data extracted included the first author, year of publication, country of origin, ethnicity, genotyping method, matching criteria, source of control, CRC ascertainment, total numbers of cases and controls and genotype frequencies of cases and controls. Ethnic backgrounds were categorized as Caucasian, and Asian. Smoking status (smoker or nonsmoker) was additionally recorded for stratified analysis. Smokers included current smokers and former smokers. Nonsmokers had never smoked. Cancer location was divided into colon cancer and rectum cancer and was also additionally recorded for the stratified analysis. To ensure the accuracy of the extracted information, the two authors checked the data extraction results and reached consensus on all of the data extracted. If different results were generated, they would check the data again and have a discussion to come to an agreement. A third reviewer (Weizhong Tang) was invited to the discussion if disagreement still existed.

\section{Quality score assessment}

The quality of eligible studies was evaluated independently by two authors (Qiliu Peng and Xue Qin) according to a set of predefined criteria (Table 1) based on the scale of Thakkinstian et al. [20]. The revised criteria cover the representativeness of cases, source of controls, ascertainment of CRC, total sample size, quality control of genotyping methods, and Hardy-Weinberg equilibrium (HWE) in the control population. Disagreements were resolved by consensus. Scores ranged from 0 (lowest) to 10 (highest). Articles with scores equal to or less than 6 were considered "low-quality" studies, whereas those with scores higher than 6 were considered "high-quality" studies. 


\section{Table 1 Scale for quality assessment}

\begin{tabular}{|c|c|}
\hline Criteria & Score \\
\hline \multicolumn{2}{|l|}{ Representativeness of cases } \\
\hline Selected from cancer registry or multiple cancer center sites & 2 \\
\hline Selected from oncology department or cancer institute & 1 \\
\hline $\begin{array}{l}\text { Selected without clearly defined sampling frame or with } \\
\text { extensive inclusion/exclusion criteria }\end{array}$ & 0 \\
\hline \multicolumn{2}{|l|}{ Source of controls } \\
\hline Population or community based & 2 \\
\hline $\begin{array}{l}\text { Both population-based and hospital-based/healthy volunteers/ } \\
\text { blood donors }\end{array}$ & 1.5 \\
\hline Hospital-based controls without colorectal cancer & 1 \\
\hline Cancer-free controls without total description & 0.5 \\
\hline Not described & 0 \\
\hline \multicolumn{2}{|l|}{ Ascertainment of colorectal cancer } \\
\hline Histological or pathological confirmation & 2 \\
\hline Diagnosis of colorectal cancer by patient medical record & 1 \\
\hline Not described & 0 \\
\hline \multicolumn{2}{|l|}{ Sample size } \\
\hline$>1000$ & 2 \\
\hline $200-1000$ & 1 \\
\hline$<200$ & 0 \\
\hline \multicolumn{2}{|l|}{ Quality control of genotyping methods } \\
\hline Clearly described a different genotyping assay to confirm the data & 1 \\
\hline Not described & 0 \\
\hline \multicolumn{2}{|l|}{ Hardy-Weinberg equilibrium } \\
\hline Hardy-Weinberg equilibrium in controls & 1 \\
\hline Hardy-Weinberg disequilibrium in controls & 0.5 \\
\hline No checking for Hardy-Weinberg disequilibrium & 0 \\
\hline
\end{tabular}

\section{Statistical analysis}

Crude odds ratios (ORs) with 95\% confidence intervals (CIs) were used to assess the association between the XPC Lys939Gln polymorphism and CRC risk. We evaluated the XPC Lys939Gln polymorphism and CRC risk using co-dominants (Gln/Gln vs. Lys/Lys and Gln/lys vs. Lys/Lys), recessive model (Gln/Gln vs. Gln/lys + Lys/ Lys), and dominant model (Gln/Gln + Gln/lys vs. Lys/ Lys). The Chi-square-based Q statistic test $[21,22]$ was used to evaluate the between-study heterogeneity. If the result of the heterogeneity test was $P_{Q}<0.10$, the pooled ORs were analyzed using the random-effects model [23]. Otherwise, the fixed-effects model [24] was selected. Subgroup analyses were performed by ethnicity, source of control, cancer location, smoking, and study quality. Sensitivity analysis was conducted by sequential omission of individual study to assess the robustness of the results. Publication bias was assessed using a Begg's funnel plot and Egger's regression asymmetry test [25]. If publication bias existed, the Duval and Tweedie non-parametric "trim and fill" method was used to adjust for it [26]. The distribution of the genotypes in the control population was tested for HWE using a goodness-of-fit Chi-square test. All analyses were performed using Stata software, version 12.0 (Stata Corp., College Station, TX). All $P$ values were two-sided. To ensure the reliability and the accuracy of the results, two authors entered the data into the statistical software programs independently with the same results.

\section{Results}

\section{Characteristics of studies}

Based on the search criteria, ten studies investigating the XPC Lys939Gln polymorphism and CRC susceptibility were identified. Two of these articles were excluded because they did not present sufficient data for calculating OR and $95 \%$ CI $[27,28]$. Manual search of references cited in the eligible studies did not reveal any additional articles. As a result, a total of 8 relevant studies containing 3,301 cases and 4,177 controls were included in the meta-analysis [29-36] (Additional file 1: Figure S1). The main characteristics of these studies were listed in Table 2. Among these publications, four studies were conducted in Caucasian descent $[29,30,33,36]$, and four were conducted in Asian descent [31,32,34,35]. Two were

Table 2 Characteristics of eligible studies

\begin{tabular}{|c|c|c|c|c|c|c|c|c|c|}
\hline $\begin{array}{c}\text { First author } \\
\text { (year) }\end{array}$ & Country & Ethnicity & $\begin{array}{c}\text { Sample size } \\
\text { (case/control) }\end{array}$ & $\begin{array}{c}\text { Genotyping } \\
\text { methods }\end{array}$ & $\begin{array}{c}\text { CRC } \\
\text { confirmation }\end{array}$ & $\begin{array}{c}\text { Source of } \\
\text { control }\end{array}$ & Matching criteria & $\begin{array}{l}\text { Quality } \\
\text { scores }\end{array}$ & $\begin{array}{c}\text { HWE } \\
\text { ( } P \text { value })\end{array}$ \\
\hline Pardini 2008 & Czech & Caucasian & $532 / 532$ & PCR-RFLP & $\mathrm{HC}$ & $\mathrm{HB}$ & Age and sex & 8 & 0.165 \\
\hline Gil 2012 & Poland & Caucasian & $133 / 100$ & PCR-RFLP & NR & $H B$ & Region & 3.5 & 0.803 \\
\hline Yue 2013 & China & Asian & $428 / 450$ & PCR-RFLP & PC & $\mathrm{HB}$ & Age and sex & 6 & 0.964 \\
\hline Aizat 2013 & Malaysia & Asian & $255 / 255$ & PCR-RFLP & $\mathrm{HC}$ & $\mathrm{HB}$ & NR & 5 & 0.316 \\
\hline Engin 2010 & Turkey & Caucasian & $110 / 116$ & PCR-RFLP & NR & $\mathrm{HB}$ & NR & 5 & 0.642 \\
\hline Wu 2011 & China & Asian & $420 / 842$ & PCR-RFLP & $\mathrm{HC}$ & PB & Age, sex, smoking and BMI & 9 & 0.639 \\
\hline Liu 2012 & China & Asian & $1028 / 1085$ & PCR-RFLP & $\mathrm{HC}$ & $\mathrm{HB}$ & Age and sex & 8 & 0.740 \\
\hline Hansen 2007 & Denmark & Caucasian & $395 / 797$ & Endpoint reading & NR & PB & Sex & 7.5 & 0.112 \\
\hline
\end{tabular}

HC, Histologically confirmed; PC, Pathologically confirmed; NR Not reported; PB, Population-based; HB, Hospital-based; HWE, Hardy-Weinberg equilibrium in control population; PCR-RFLP, Polymerase chain reaction-restriction fragment length polymorphism. 
population-based studies [34,36] and six were hospitalbased studies [29-33,35]. Three of these studies presented XPC Lys939Gln polymorphism genotype distributions according to smoking status (smokers and nonsmokers). The cases were histologically or pathologically confirmed as CRC in five studies [29,31,32,34,35]. Controls were mainly healthy or hospital-based populations and matched with age and gender. The genotype distributions of the controls in all of the included studies were consistent with HWE.

\section{Meta-analysis}

As shown in Table 3, we found that the XPC Lys939Gln polymorphism was significantly correlated with increased CRC risk when all studies were pooled into the metaanalysis (Gln/lys vs. Lys/Lys: OR $=1.293$, 95\% CI 1.1691.430, $P=0.000 ; \mathrm{Gln} / \mathrm{G} \ln +\mathrm{G} \ln / \mathrm{lys}$ vs. Lys/Lys: $\mathrm{OR}=$ $1.260,95 \% \mathrm{CI} 1.145-1.388, P=0.000)$. In subgroup analysis by ethnicity, significant increased CRC risk was found in Asian populations (Gln/lys vs. Lys/Lys: $\mathrm{OR}=1.345$, 95\% CI 1.187-1.523, $P=0.000$, Figure 1; Gln/Gln + Gln/lys vs. Lys/Lys: $\mathrm{OR}=1.317,95 \%$ CI 1.170-1.484, $P=0.000$, Figure 2), but not in Caucasian populations. In stratified analysis according to study quality, significant increased CRC risk was found in high quality studies (Gln/lys vs. Lys/Lys: OR $=1.290,95 \%$ CI 1.148-1.450, $P=0.000 ; \mathrm{Gln} /$ Gln + Gln/lys vs. Lys/Lys: OR $=1.248$, 95\% CI $1.117-$ $1.395, P=0.000$ ), but not in low quality studies. In subgroup analysis by smoking status, significant increased CRC risk was observed in nonsmokers (Gln/Gln + Gln/lys vs. Lys/Lys: $\mathrm{OR}=1.286,95 \% \mathrm{CI} 1.020-1.622, P=0.033$ ), but not in smokers. In subgroup analysis according to source of control, significant increased CRC risk was found in both hospital-based studies (Gln/lys vs. Lys/Lys: $\mathrm{OR}=1.335,95 \% \mathrm{CI} 1.182-1.507, \quad P=0.000 ; \mathrm{Gln} / \mathrm{Gln}+$ Gln/lys vs. Lys/Lys: $\mathrm{OR}=1.282$, 95\% CI 1.142-1.439, $P=$ 0.000 ) and population-based studies (Gln/lys vs. Lys/Lys: $\mathrm{OR}=1.204,95 \% \mathrm{CI} 1.003-1.444, \quad P=0.046 ; \mathrm{Gln} / \mathrm{Gln}+$ Gln/lys vs. Lys/Lys: OR $=1.213$, 95\% CI 1.020-1.443, $P=$ $0.029)$. However, in subgroup analysis according to cancer location, statistical significant association was not detected in both colon cancer patients and rectum cancer subjects.

\section{Heterogeneity analysis}

Heterogeneity between studies was estimated using the Chi-square-based $\mathrm{Q}$ test and the significance of which was set at $P_{Q}<0.10$. There was no statistical significant heterogeneity among studies when all eligible studies were pooled into the meta-analysis. In subgroup analyses according to ethnicity, source of control, cancer location, smoking, and study quality, statistical significant heterogeneity was not observed in all subgroups (Table 3).

\section{Sensitivity analysis}

Sensitivity analysis was performed by sequential omission of individual studies. For analyses of pooling more than three individual studies, the significance of the pooled ORs was not influenced excessively by omitting any single study (Figure 3), indicating that our results were statistical robust.

\section{Publication bias}

Begg's funnel plot and Egger's test were performed to assess the publication bias of literatures in all comparison models. The shape of the funnel plot did not reveal any evidence of obvious asymmetry (Figure 4). Then, the Egger's test was used to provide statistical evidence of funnel plot symmetry. All the $\mathrm{p}$ values of Egger's tests were more than 0.05 ( $P=0.660$ for GlnGln vs. LysLys; $\mathrm{P}=0.584$ for Glnlys vs. LysLys; $\mathrm{P}=0.670$ for dominant model GlnGln + Glnlys vs. LysLys; and P $=0.627$ for recessive model GlnGln vs. Glnlys + LysLys), providing statistical evidence for the funnel plots' symmetry. The results suggested that publication bias was not evident in this meta-analysis.

\section{Discussion}

Maintenance of genomic integrity by DNA repair genes is an essential component of normal cell homeostasis necessary to cell growth, differentiation, and apoptosis $[37,38]$. Increasing evidence indicating that reduced DNA repair capacity, due to various DNA repair gene polymorphisms, is associated with increased risk and susceptibility to human solid tumors $[16,39,40]$. XPC is a key member in the NER pathway. It is involved in the recognition and initiation of the genome repair of NER pathway [10,41,42]. Polymorphisms in the XPC gene may alter DNA repair capacity of the NER pathway, which further play a critical role in carcinogenesis [43]. To date, several epidemiological studies have evaluated the association between XPC Lys939Gln polymorphism and CRC risk, but the results remain inconclusive. Meta-analysis has been recognized as an important tool to more precisely define the effect of selected genetic polymorphisms on the risk for disease and to identify potential important sources of between-study heterogeneity [2]. To derive a more precise estimation of the relationship, we performed this meta-analysis. Our meta-analysis based on 8 casecontrol studies suggested that the XPC Lys939Gln polymorphism contributes to increased CRC susceptibility.

In subgroup analysis by ethnicity, statistical significant increased CRC risk was detected in Asians. However, no significant association was found in Caucasians. Actually, it might not be uncommon for the same polymorphism playing different roles in cancer susceptibility among different ethnic populations, because cancer is a complicated multi-genetic disease, and different genetic backgrounds 
Table 3 Meta-analysis of XPC Lys939GIn polymorphism and colorectal cancer risk

\begin{tabular}{|c|c|c|c|c|c|c|c|c|c|}
\hline \multirow[t]{2}{*}{ Analysis } & \multirow[t]{2}{*}{$\begin{array}{l}\text { No. of } \\
\text { studies }\end{array}$} & \multicolumn{2}{|c|}{$\begin{array}{l}\text { Homozygote } \\
\text { (Gln/Gln vs. Lys/Lys) }\end{array}$} & \multicolumn{2}{|c|}{$\begin{array}{l}\text { Heterozygote } \\
\text { (Gln/lys vs. Lys/Lys) }\end{array}$} & \multicolumn{2}{|c|}{$\begin{array}{c}\text { Dominant model } \\
\text { (Gln/Gln + Gln/lys vs. Lys/Lys) }\end{array}$} & \multicolumn{2}{|c|}{$\begin{array}{c}\text { Recessive model } \\
\text { (Gln/Gln vs. Gln/lys + Lys/Lys) }\end{array}$} \\
\hline & & OR $(95 \% \mathrm{Cl})$ & $P / P_{\mathrm{Q}}$ & OR $(95 \% \mathrm{Cl})$ & $P / P_{Q}$ & OR $(95 \% \mathrm{Cl})$ & $P / P_{\mathrm{Q}}$ & OR $(95 \% \mathrm{Cl})$ & $P / P_{Q}$ \\
\hline Overall & 8 & $1.134(0.979-1.315)$ & $0.094 / 0.495$ & $1.293(1.169-1.430)$ & $0.000 / 0.943$ & $1.260(1.145-1.388)$ & $0.000 / 0.955$ & $0.976(0.853-1.117)$ & $0.722 / 0.211$ \\
\hline \multicolumn{10}{|l|}{ Ethnicity } \\
\hline Caucasian & 4 & $1.038(0.818-1.318)$ & $0.758 / 0.885$ & $1.200(0.983-1.426)$ & 0.098/0.918 & $1.159(0.984-1.365)$ & $0.077 / 0.951$ & $0.915(0.740-1.133)$ & $0.417 / 0.644$ \\
\hline Asian & 4 & $1.199(0.993-1.446)$ & 0.059/0.180 & $1.345(1.187-1.523)$ & $0.000 / 0.878$ & $1.317(1.170-1.484)$ & $0.000 / 0.978$ & $1.078(0.809-1.436)$ & $0.607 / 0.061$ \\
\hline \multicolumn{10}{|c|}{ Source of control } \\
\hline $\mathrm{HB}$ & 6 & $1.091(0.915-1.302)$ & 0.333/0.399 & $1.335(1.182-1.507)$ & $0.000 / 0.961$ & $1.282(1.142-1.439)$ & $0.000 / 0.945$ & $0.922(0.785-1.082)$ & $0.318 / 0.184$ \\
\hline PB & 2 & $1.243(0.950-1.627)$ & $0.112 / 0.440$ & $1.204(1.003-1.444)$ & $0.046 / 0.528$ & $1.213(1.020-1.443)$ & $0.029 / 0.436$ & $1.122(0.875-1.438)$ & $0.366 / 0.545$ \\
\hline \multicolumn{10}{|c|}{ Cancer location } \\
\hline Colon & 2 & $1.105(0.809-1.510)$ & $0.528 / 0.327$ & $1.278(0.983-1.601)$ & $0.093 / 0.851$ & $1.234(0.996-1.528)$ & $0.054 / 0.826$ & $0.953(0.719-1.264)$ & $0.738 / 0.226$ \\
\hline Rectum & 2 & $1.253(0.902-1.741)$ & $0.179 / 0.482$ & $1.200(0.941-1.532)$ & $0.142 / 0.471$ & $1.217(0.967-1.531)$ & $0.094 / 0.419$ & $1.140(0.847-1.534)$ & $0.388 / 0.643$ \\
\hline \multicolumn{10}{|l|}{ Smoking } \\
\hline Yes & 3 & $1.299(0.841-2.006)$ & $0.237 / 0.169$ & $1.164(0.871-1.556)$ & $0.305 / 0.825$ & $1.118(0.900-1.389)$ & $0.314 / 0.455$ & $1.185(0.794-1.770)$ & $0.405 / 0.261$ \\
\hline No & 2 & $1.256(0.620-2.542)$ & $0.527 /-$ & $1.284(0.817-2.018)$ & $0.279 /-$ & $1.286(1.020-1.622)$ & $0.033 / 0.972$ & $1.117(0.570-2.187)$ & $0.747 /-$ \\
\hline \multicolumn{10}{|l|}{ Study quality } \\
\hline High quality & 4 & $1.093(0.920-1.299)$ & $0.313 / 0.547$ & $1.290(1.148-1.450)$ & $0.000 / 0.531$ & $1.248(1.117-1.395)$ & $0.000 / 0.680$ & $0.950(0.811-1.114)$ & $0.530 / 0.310$ \\
\hline Low quality & 4 & $1.257(0.944-1.674)$ & $0.118 / 0.304$ & $1.201(0.963-1.563)$ & $0.091 / 0.996$ & $1.278(0.971-1.552)$ & $0.108 / 0.929$ & $1.046(0.809-1.353)$ & $0.733 / 0.128$ \\
\hline
\end{tabular}

$P_{\mathrm{Q}} \mathrm{P}$ values of Q-test for heterogeneity test. OR, odds ratio; $\mathrm{Cl}$, confidence intervals; $\mathrm{HWE}$, Hardy-Weinberg equilibrium. 


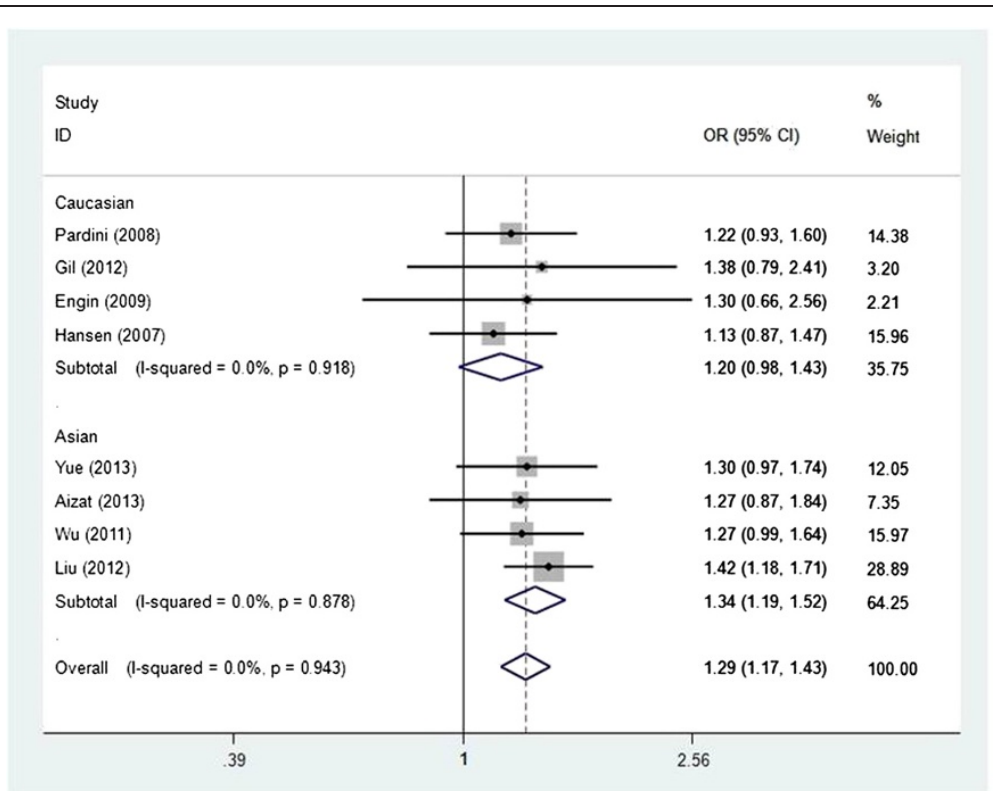

Figure 1 Forest plot of subgroup analysis by ethnicity on the association between XPC Lys939Gln polymorphism and CRC risk using a fixed-effect model (GInlys vs. LysLys).

may contribute to the discrepancy. Nevertheless, owing to the limited number of relevant studies included in the meta-analysis, the observed association between XPC Lys939Gln polymorphism and CRC risk is likely to be caused by chance because study with small sample sizes may have insufficient statistical power to detect a slight effect or may have generated a fluctuated risk estimate. Currently there were only four studies on XPC
Lys939Gln polymorphism and CRC risk for Asian populations, and Caucasian populations, respectively. Therefore, the observed results of our study should be interpreted with caution.

When stratified according to the quality score of the articles, statistical significant increased CRC risk was observed in high quality studies but not in low quality studies. The possible reason for the discrepancy may be

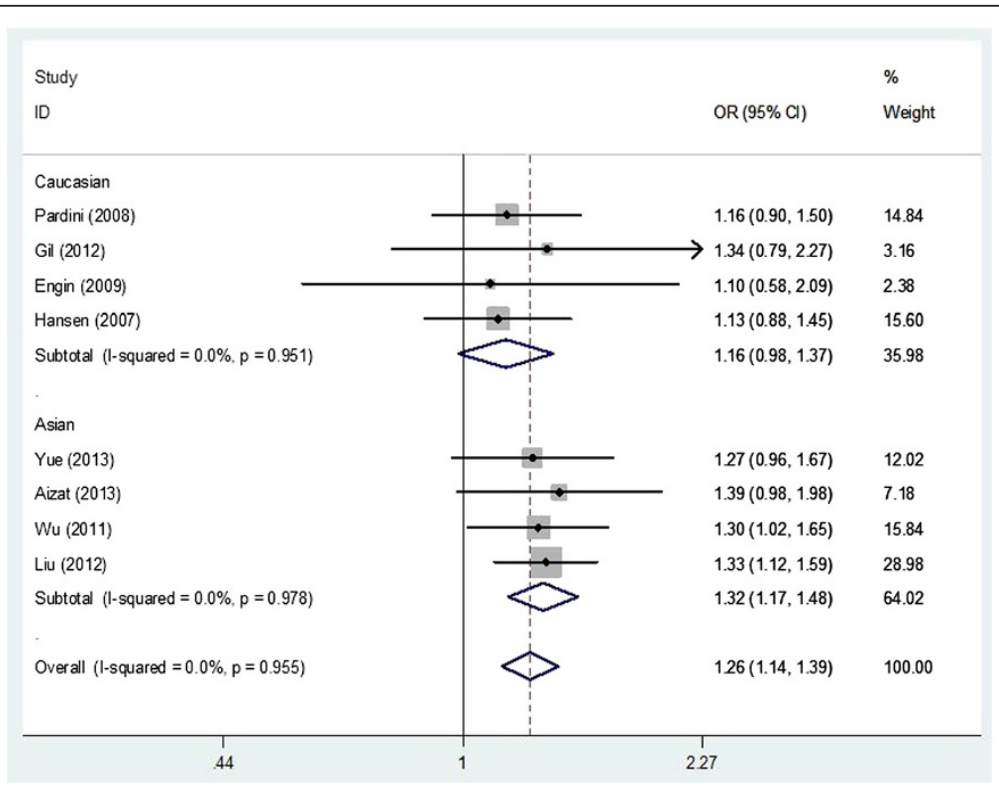

Figure 2 Forest plot of subgroup analysis by ethnicity on the association between XPC Lys939Gln polymorphism and CRC risk using a fixed-effect model (dominant model GlnGln + Glnlys vs. LysLys). 

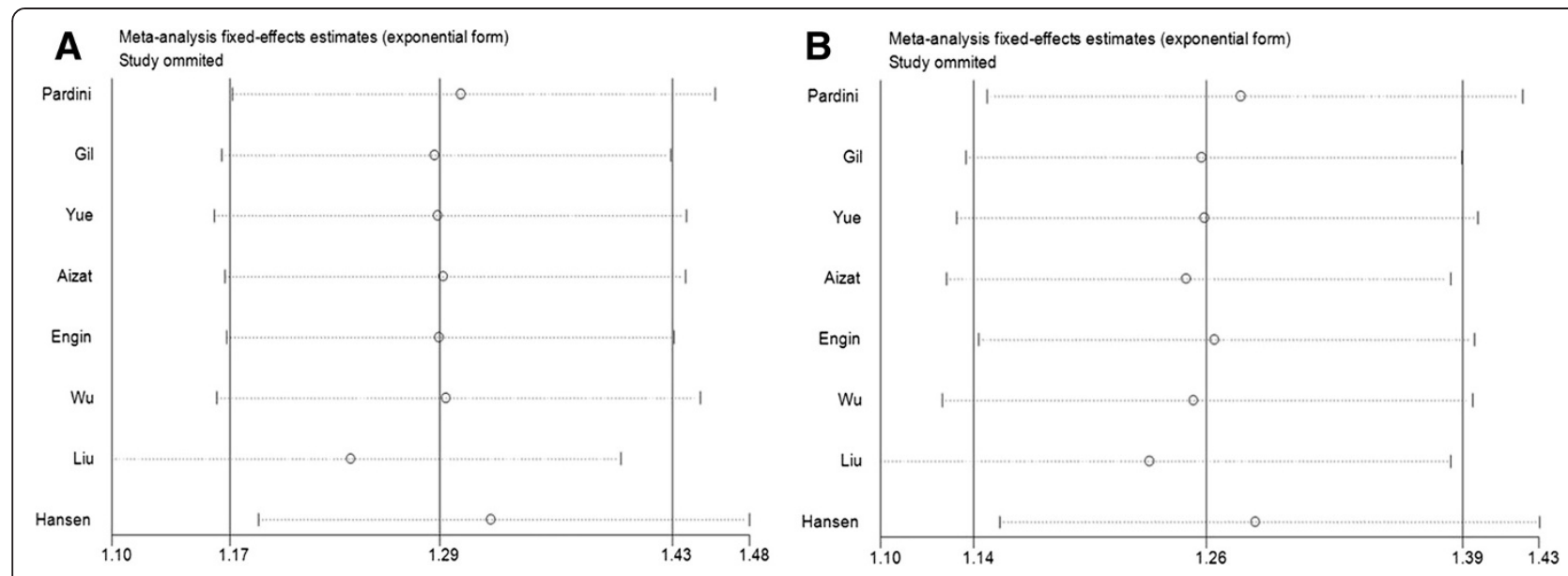

Figure 3 Sensitivity analysis of XPC Lys939GIn polymorphism and CRC risk in the overall populations. This figures show the influence of individual studies on the summary OR. The middle vertical axis indicates the overall OR and the two vertical axes indicate its $95 \% \mathrm{Cl}$. Every hollow round indicates the pooled OR when the left study is omitted in this meta-analysis. The two ends of every broken line represent the $95 \% \mathrm{Cl}$.

A GInlys vs. LysLys; B dominant model GlnGln + GInlys vs. LysLys.

that the existence of selection bias and recall bias in the low quality studies. In addition, genotyping methods without quality control in studies of low quality should be also considered when deciphering these inconsistent results. In subgroup analysis according to the source of control, statistical significant increased CRC risk was found in both population-based studies and hospitalbased studies. However, the ORs and 95\% CIs differ largely in these two subgroups. The reason may be that the hospital-based studies have a high risk of producing unreliable results because hospital-based controls may not always be truly representative of the general population. Therefore, a methodologically preferable design, such as using a proper and representative population-based high quality study, is of great value in case-control studies.

It is well established that the carcinogenesis of CRC is a result of the interaction between environmental factors and genetic background $[18,44]$. Besides the role of genetic variants, smoking behavior shows an important effect on the CRC susceptibility. It has been reported that smoking increased CRC risk threefold [36]. It is thought that smoking increased cancer risk due to chemicals such as hydrocarbons, arylamines, nitrosamines, and the formation of reactive oxygen species as by-products of the above compounds [45] that are known to induce bulky adducts, base damage, and DNA strand breaks. DNA repair mechanisms are paramount in correcting the changes on DNA and provide unmutated DNA while replication goes on [46]. The XPC protein plays a crucial role in repairing the DNA damage caused by tobacco smoke. Individuals with the $X P C$ variant genotype may possess deficient DNA repair capability. Accordingly, the XPC protein product may be less efficient in repairing the DNA lesions induced by tobacco smoke, and thereby
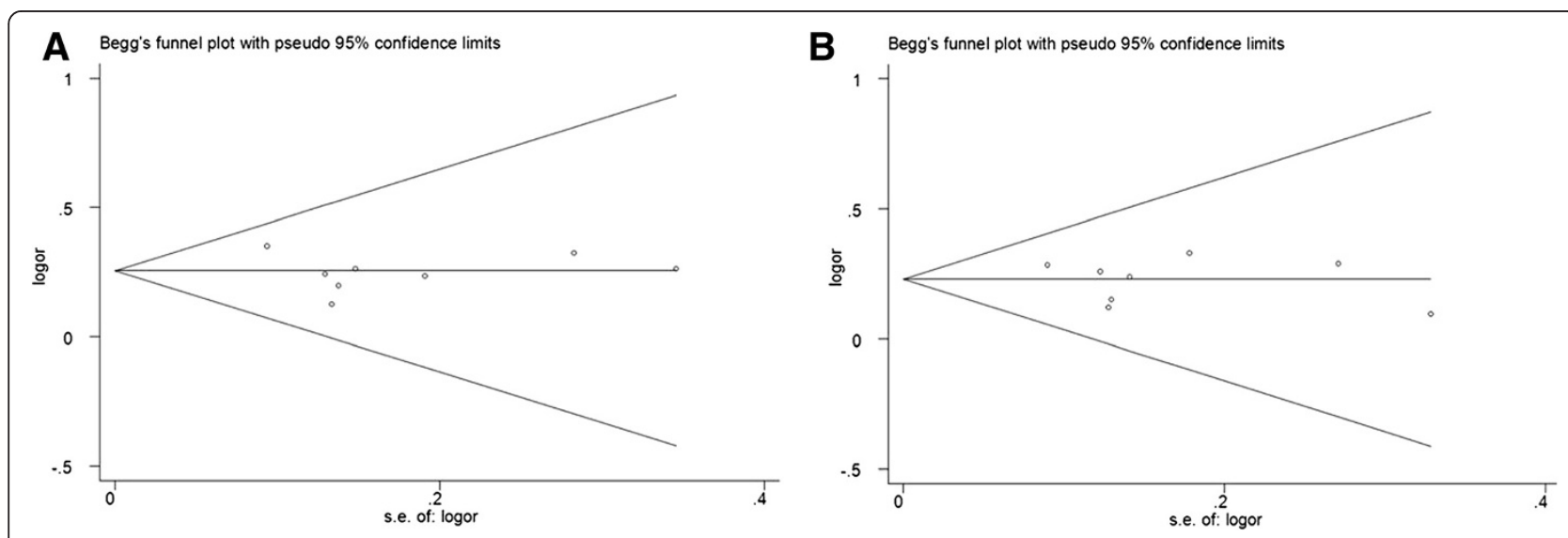

Figure 4 Funnel plots for publication bias of the meta-analysis on the association between XPC Lys939Gln polymorphism and CRC risk in the overall populations. A Glnlys vs. LysLys; B dominant model GlnGln + Glnlys vs. LysLys. 
could enhance the susceptibility, favoring the development of CRC. Therefore, we carried out subgroup analysis according to smoking status. Our results showed an increased CRC risk in nonsmokers but not in smokers, which was inconsistent with the hypothesis above. The results should be interpreted with caution because of the limited numbers of the original studies. Therefore, further studies concerning stratification for smoking are needed to increase power for the association estimation.

Some possible limitations in this meta-analysis should be acknowledged. First, in subgroup analysis by ethnicity, the included studies regarded only Asians and Caucasians. Data concerning other ethnicities such as Africans were not found. Thus, additional studies are warranted to evaluate the effect of this functional polymorphism on CRC risk in different ethnicities, especially in Africans. Second, our results were based on unadjusted estimates. We did not perform the analysis adjusted for other covariates such as age, drinking status, environment factors, and so on, because of the unavailable original data of the eligible studies. Third, in subgroup analyses by ethnicity, cancer location, and smoking status, the sample size of the subgroups was relatively small for stratified analyses, which may lead to relatively weak power to detect the real relationship.

\section{Conclusions}

Our meta-analysis provided a more precise estimation based on larger sample size compared with the individual studies. Our study suggested that the $X P C$ is a candidate gene for CRC susceptibility. The XPC Lys939Gln polymorphism may play an important role in CRC development especially among Asians and nonsmokers. In order to further verify our findings, large well designed epidemiological studies are warranted.

\section{Additional file}

Additional file 1: Flow diagram of included studies for this meta-analysis.

\begin{abstract}
Abbreviations
CRC: Colorectal cancer; HWE: Hardy-Weinberg equilibrium; NER: Nucleotide excision repair; XPC: Xeroderma pigmentosum complementation group C; SNP: Single nucleotide polymorphism; OR: Odds ratio; Cl: Confidence interval.
\end{abstract}

\section{Competing interest}

All authors declare that they have no competing interest in relation to this study.

\section{Authors' contributions}

$\mathrm{QP}, \mathrm{XQ}$ performed the literature search, data extraction, statistical analysis and drafted the manuscript. $\mathrm{QP}, \mathrm{XL}, \mathrm{WT}, \mathrm{ZC}$, and $\mathrm{RL}$ participated in data extraction. QP, XQ, ZC, SL supervised the literature search, data extraction, statistical analysis and drafted the manuscript. All authors read and approved the final manuscript.

\section{Acknowledgements}

This work was not supported by any kind of fund.

\section{Author details}

${ }^{1}$ Department of Clinical Laboratory, First Affiliated Hospital of Guangx Medical University, Nanning 530021, Guangxi, China. ${ }^{2}$ Department of Anal and Colorectal Surgery, First Affiliated Hospital of Guangxi Medical University, Nanning, Guangxi, China. ${ }^{3}$ Department of Occupational Health and Environmental Health, School of Public Health at Guangxi Medical University, Nanning, Guangxi, China. ${ }^{4}$ Department of Medicine Research, First Affiliated Hospital of Guangxi Medical University, Nanning, Guangxi, China.

Received: 3 April 2014 Accepted: 15 May 2014

Published: 19 June 2014

\section{References}

1. Jemal A, Siegel R, Xu J, Ward E: Cancer statistics, 2010. CA Cancer J Clin 2010, 60:277-300.

2. Fan NJ, Kang R, Ge XY, Li M, Liu Y, Chen HM, Gao CF: Identification alpha-2-HS-glycoprotein precursor and tubulin beta chain as serology diagnosis biomarker of colorectal cancer. Diagn Pathol 2014, 9:53.

3. Ferlay J, Parkin DM, Steliarova-Foucher E: Estimates of cancer incidence and mortality in Europe in 2008. Eur J Cancer 2010, 46:765-781.

4. Sung JJ, Lau JY, Goh KL, Leung WK: Increasing incidence of colorectal cancer in Asia: implications for screening. Lancet Oncol 2005, 6:871-876.

5. Liu Y, Tang W, Wang J, Xie L, Li T, He Y, Qin X, Li S: Clinicopathological and prognostic significance of S100A4 overexpression in colorectal cancer: a meta-analysis. Diagn Pathol 2013, 8:181.

6. Zhao P, Dai M, Chen W, Li N: Cancer trends in China. Jpn J Clin Oncol 2010, 40:281-285

7. Giovannucci E: An updated review of the epidemiological evidence that cigarette smoking increases risk of colorectal cancer. Cancer Epidemiol Biomarkers Prev 2001, 10:725-731.

8. Terry P, Giovannucci E, Michels KB, Bergkvist L, Hansen H, Holmberg L, Wolk A: Fruit, vegetables, dietary fiber, and risk of colorectal cancer. J Natl Cancer Inst 2001, 93:525-533.

9. Qiu L, Wang Z, Shi X: Associations between XPC polymorphisms and risk of cancers: A meta-analysis. Eur J Cancer 2008, 44:2241-2253.

10. Thoma BS, Vasquez KM: Critical DNA damage recognition functions of XPC-hHR23B and XPA-RPA in nucleotide excision repair. Mol Carcinog 2003, 38:1-13.

11. Tapias A, Auriol J, Forget D, Enzlin JH, Scharer OD, Coin F, Coulombe B, Egly JM: Ordered conformational changes in damaged DNA induced by nucleotide excision repair factors. J Biol Chem 2004, 279:19074-19083.

12. Leibeling $D$, Laspe $P$, Emmert $S$ : Nucleotide excision repair and cancer. J Mol Histol 2006, 37:225-238.

13. Khan SG, Muniz-Medina V, Shahlavi T, Baker CC, Inui H, Ueda T, Emmert S, Schneider TD, Kraemer KH: The human XPC DNA repair gene: arrangement, splice site information content and influence of a single nucleotide polymorphism in a splice acceptor site on alternative splicing and function. Nucleic Acids Res 2002, 30:3624-3631.

14. Blankenburg S, Konig IR, Moessner R, Laspe P, Thoms KM, Krueger U, Khan SG, Westphal G, Berking C, Volkenandt M, Reich K, Neumann C, Ziegler A, Kraemer $\mathrm{KH}$, Emmert S: Assessment of 3 xeroderma pigmentosum group $\mathrm{C}$ gene polymorphisms and risk of cutaneous melanoma: a case-control study. Carcinogenesis 2005, 26:1085-1090

15. Sanyal S, Festa F, Sakano S, Zhang Z, Steineck G, Norming U, Wijkstrom H, Larsson P, Kumar R, Hemminki K: Polymorphisms in DNA repair and metabolic genes in bladder cancer. Carcinogenesis 2004, 25:729-734.

16. Zhang L, Zhang Z, Yan W: Single nucleotide polymorphisms for DNA repair genes in breast cancer patients. Clin Chim Acta 2005, 359:150-155.

17. Casas JP, Hingorani AD, Bautista LE, Sharma P: Meta-analysis of genetic studies in ischemic stroke: thirty-two genes involving approximately 18,000 cases and 58,000 controls. Arch Neurol 2004, 61:1652-1661.

18. Wangefjord S, Brandstedt J, Lindquist KE, Nodin B, Jirstrom $K$, Eberhard J: Associations of beta-catenin alterations and MSI screening status with expression of key cell cycle regulating proteins and survival from colorectal cancer. Diagn Pathol 2013, 8:10.

19. Stroup DF, Berlin JA, Morton SC, Olkin I, Williamson GD, Rennie D, Moher D, Becker BJ, Sipe TA, Thacker SB: Meta-analysis of observational studies in 
epidemiology: a proposal for reporting. Meta-analysis Of Observational Studies in Epidemiology (MOOSE) group. JAMA 2000, 283:2008-2012.

20. Thakkinstian A, McEvoy M, Minelli C, Gibson P, Hancox B, Duffy D, Thompson J, Hall I, Kaufman J, Leung TF, Helms PJ, Hakonarson H, Halpi E, Navon R, Attia J: Systematic review and meta-analysis of the association between \{beta\}2-adrenoceptor polymorphisms and asthma: a HuGE review. Am J Epidemiol 2005, 162:201-211.

21. Lau J, loannidis JP, Schmid CH: Quantitative synthesis in systematic reviews. Ann Intern Med 1997, 127:820-826.

22. Higgins JP, Thompson SG: Quantifying heterogeneity in a meta-analysis. Stat Med 2002, 21:1539-1558.

23. DerSimonian R, Laird N: Meta-analysis in clinical trials. Control Clin Trials 1986, 7:177-188.

24. Mantel N, Haenszel W: Statistical aspects of the analysis of data from retrospective studies of disease. J Nat/ Cancer Inst 1959, 22:719-748.

25. Egger M, Davey Smith G, Schneider M, Minder C: Bias in meta-analysis detected by a simple, graphical test. BMJ 1997, 315:629-634.

26. Duval S, Tweedie R: Trim and fill: A simple funnel-plot-based method of testing and adjusting for publication bias in meta-analysis. Biometrics 2000, 56:455-463.

27. Slyskova J, Naccarati A, Pardini B, Polakova V, Vodickova L, Smerhovsky Z, Levy M, Lipska L, Liska V, Vodicka P: Differences in nucleotide excision repair capacity between newly diagnosed colorectal cancer patients and healthy controls. Mutagenesis 2012, 27:225-232.

28. Berndt SI, Platz EA, Fallin MD, Thuita LW, Hoffman SC, Helzlsouer KJ: Genetic variation in the nucleotide excision repair pathway and colorectal cancer risk. Cancer Epidemiol Biomarkers Prev 2006, 15:2263-2269.

29. Pardini B, Naccarati A, Novotny J, Smerhovsky Z, Vodickova L, Polakova V, Hanova M, Slyskova J, Tulupova E, Kumar R, Bortlik M, Barale R, Hemminki K, Vodicka P: DNA repair genetic polymorphisms and risk of colorectal cancer in the Czech Republic. Mutat Res 2008, 638:146-153.

30. Gil J, Ramsey D, Stembalska A, Karpinski P, Pesz KA, Laczmanska I, Leszczynski P, Grzebieniak Z, Sasiadek MM: The C/A polymorphism in intron 11 of the XPC gene plays a crucial role in the modulation of an individual's susceptibility to sporadic colorectal cancer. Mol Biol Rep 2012, 39:527-534.

31. Yue AM, Xie ZB, Zhao HF, Guo SP, Shen YH, Wang HP: Associations of $A B C B 1$ and XPC genetic polymorphisms with susceptibility to colorectal cancer and therapeutic prognosis in a Chinese population. Asian Pac J Cancer Prev 2013, 14:3085-3091.

32. Ahmad Aizat AA, Siti Nurfatimah MS, Aminudin MM, Ankathil R: XPC Lys939GIn polymorphism, smoking and risk of sporadic colorectal cancer among Malaysians. World J Gastroenterol 2013, 19:3623-3628.

33. Engin AB, Karahalil B, Engin A, Karakaya AE: Oxidative stress, Helicobacter pylori, and OGG1 Ser326Cys, XPC Lys939GIn, and XPD Lys751GIn polymorphisms in a Turkish population with colorectal carcinoma. Genet Test Mol Biomarkers 2010, 14:559-564.

34. Wu Y, Jin M, Liu B, Liang X, Yu Y, Li Q, Ma X, Yao K, Chen K: The association of XPC polymorphisms and tea drinking with colorectal cancer risk in a Chinese population. Mol Carcinog 2011, 50:189-198.

35. Liu D, Wu HZ, Zhang YN, Kang H, Sun MJ, Wang EH, Yang XL, Lian MQ, Yu ZJ, Zhao L, Olopade OI, Wei MJ: DNA repair genes XPC, XPG polymorphisms: relation to the risk of colorectal carcinoma and therapeutic outcome with Oxaliplatin-based adjuvant chemotherapy. Mol Carcinog 2012, 51(Suppl 1): E83-E93.

36. Hansen RD, Sorensen M, Tjonneland A, Overvad K, Wallin H, Raaschou-Nielsen O, Vogel U: XPA A23G, XPC Lys939Gln, XPD Lys751Gln and XPD Asp312Asn polymorphisms, interactions with smoking, alcohol and dietary factors, and risk of colorectal cancer. Mutat Res 2007, 619:68-80.

37. Wood RD, Mitchell M, Sgouros J, Lindahl T: Human DNA repair genes. Science 2001, 291:1284-1289.

38. Hoeijmakers JH: Genome maintenance mechanisms for preventing cancer. Nature 2001, 411:366-374.

39. Garcia-Closas M, Malats N, Real FX, Welch R, Kogevinas M, Chatterjee N, Pfeiffer R, Silverman D, Dosemeci M, Tardon A, Serra C, Carrato A, GarciaClosas R, Castano-Vinyals G, Chanock S, Yeager M, Rothman N: Genetic variation in the nucleotide excision repair pathway and bladder cancer risk. Cancer Epidemiol Biomarkers Prev 2006, 15:536-542.

40. Cheng D, Shi H, Zhang K, Yi L, Zhen G: RAD51 Gene 135G/C polymorphism and the risk of four types of common cancers: a meta-analysis. Diagn Pathol 2014, 9:18.
41. Wood RD: Nucleotide excision repair in mammalian cells. J Biol Chem 1997, 272:23465-23468.

42. Sugasawa K, Ng JM, Masutani C, Iwai S, van der Spek PJ, Eker AP, Hanaoka F, Bootsma D, Hoeijmakers $\mathrm{JH}$ : Xeroderma pigmentosum group $\mathrm{C}$ protein complex is the initiator of global genome nucleotide excision repair. Mol Cell 1998, 2:223-232

43. Goode EL, Ulrich CM, Potter JD: Polymorphisms in DNA repair genes and associations with cancer risk. Cancer Epidemiol Biomarkers Prev 2002, 11:1513-1530.

44. Wang L, Cai S, Teng Z, Zhao X, Chen X, Bai X: Insulin therapy contributes to the increased risk of colorectal cancer in diabetes patients: $a$ meta-analysis. Diagn Pathol 2013, 8:180.

45. Benhamou S, Sarasin A: ERCC2 /XPD gene polymorphisms and lung cancer: a HuGE review. Am J Epidemiol 2005, 161:1-14.

46. Friedberg EC: DNA damage and repair. Nature 2003, 421:436-440.

doi:10.1186/1746-1596-9-120

Cite this article as: Peng et al: XPC Lys939Gln polymorphism contributes to colorectal cancer susceptibility: evidence from a meta-analysis.

Diagnostic Pathology 2014 9:120.

\section{Submit your next manuscript to BioMed Central and take full advantage of:}

- Convenient online submission

- Thorough peer review

- No space constraints or color figure charges

- Immediate publication on acceptance

- Inclusion in PubMed, CAS, Scopus and Google Scholar

- Research which is freely available for redistribution

Submit your manuscript at www.biomedcentral.com/submit
C Biomed Central 